\title{
Endoscopic ultrasound-guided transgastric drain- age of a complex multiloculated peritoneal fluid collection as rare complication of lupus peritonitis
}

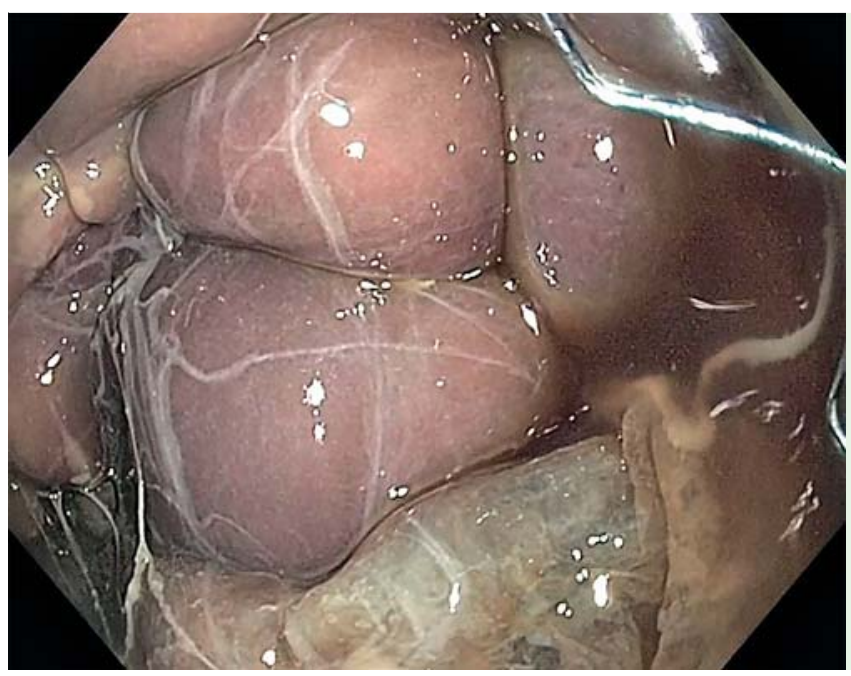

Fig. 1 Endoscopic appearance of the cyst cavity showing small amount of fluid, thin membranous septae, and whitish, cheesylooking material.

A 23-year-old woman with an 8-year history of systemic lupus erythematosus (SLE) complicated by recurrent peritonitis presented with abdominal pain and distension.

Abdominal computed tomography (CT) demonstrated a new $12 \times 15 \times 23 \mathrm{~cm}$ fluid collection in the mid-abdomen that was separate from the adnexa and without intracystic gas. Ultrasound demonstrated a complex multiloculated fluid collection with innumerable septations. Ultrasound-guided aspirate of a cystic portion yielded serosanguinous fluid with a nucleated cell count of 20775 , 95\% neutrophils, and normal amylase, lipase, and CEA. Results of Gram staining, acid-fast staining, and bacterial and fungal cultures of the aspirate were negative. Interventional radiology-guided placement of a percutaneous pigtail catheter yielded minimal drainage, and abdominal pain and distension persisted.

Endoscopic ultrasound (EUS) showed a complex, thick-walled, loculated fluid collection that was separate from the stomach, pancreas, spleen, and kidneys. EUSguided cystgastrostomy was performed with an $18 \times 60 \mathrm{~mm}$ fully covered metal stent (TaeWoong Medical, Gyeonggi-do, South Korea). Endoscopic evaluation of the cyst cavity showed a small amount of fluid, thin membranous septae, and whitish, cheesy-looking material. Biopsies from the cavity wall showed necrotic tissue of uncertain etiology.

On repeat endoscopy ( $\bullet$ Fig. $1, \bullet$ Video 1$)$, the thin septae were bluntly dissected using the tip of the endoscope, and larger chunks of reddish tissue were removed using a snare and Roth net. Repeat biopsies showed suppurative inflammation, liquefactive necrosis, and fibrinous thrombus. The patient's symptoms resolved, and repeat CT 2 months later demonstrated resolution of the collection. EUS confirmed this finding, and the cystgastrostomy stent was removed uneventfully.

At 1-year follow-up, the patient had no signs or symptoms suggestive of fluid reaccumulation.

Based on the inflammatory picture of the biopsied cavity walls with negative histologic, microbiologic, and cytologic analysis, we suspect this complex multiloculated collection was a rare complication of lupus peritonitis. This report highlights the diagnostic and therapeutic role of EUS-guided cystgastrostomy in the management of this rare complication of SLE.

Endoscopy_UCTN_Code_TTT_1AS_2AC

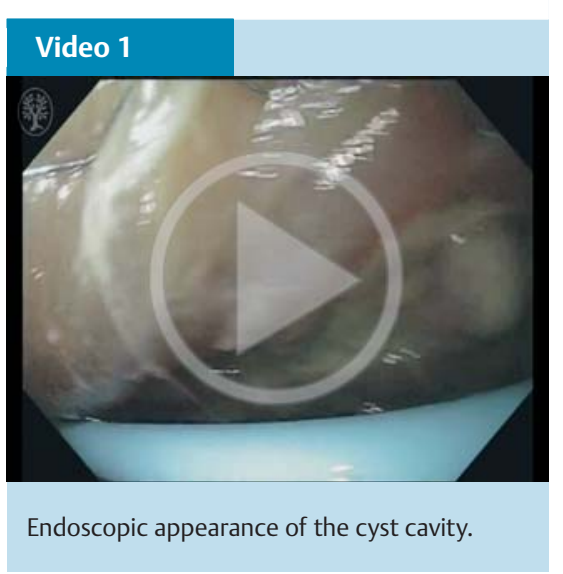

Competing interests: None

\section{Farid Jalali, Jason Samarasena, John G. Lee}

H. H. Chao Comprehensive Digestive Disease Center, Division of Gastroenterology, Department of Medicine, Irvine Medical Center, University of California, Orange, California, United States

\section{Bibliography}

Dol http://dx.doi.org/ 10.1055/s-0042-100807 Endoscopy 2016; 48: E39 (C) Georg Thieme Verlag KG Stuttgart · New York ISSN 0013-726X

\section{Corresponding author}

John G. Lee, MD

H. H. Chao Comprehensive

Digestive Disease Center

Division of Gastroenterology

Department of Medicine

Irvine Medical Center

University of California

Orange

CA 92868

USA

Fax: +1-714-456-7753

jglee@uci.edu 